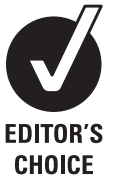

1 Department of Public Health Melbourne Sexual Health Centre, Alfred Hospital and School of Population Health University of Melbourne, Carlton, Victoria, Australia ${ }^{2}$ Centre for Women's Health, Gender and Society, School of Population Health, University of Melbourne, Carlton, Victoria, Australia

${ }^{3}$ The Kirby Institute, Sydney Sexual Health Centre, University of New South Wales, Sydney, New South Wales, Australia ${ }^{4}$ Department of Epidemiology and Preventive Medicine, Melbourne Sexual Health Centre, Alfred Hospital, Monash University, Prahran, Victoria

\section{Correspondence to}

Professor Christopher Fairley,

Melbourne Sexual Health

Centre, Alfred Hospital and

School of Population Health,

University of Melbourne, 580

Swanston Street, Carlton,

Victoria 3053, Australia;

cfairley@unimelb.edu.au

Accepted 7 September 2011

Published Online First

4 October 2011

\title{
The near disappearance of genital warts in young women 4 years after commencing a national human papillomavirus (HPV) vaccination programme
}

\author{
Tim R H Read, ${ }^{1}$ Jane S Hocking, ${ }^{2}$ Marcus Y Chen, ${ }^{1}$ Basil Donovan, ${ }^{3}$ \\ Catriona S Bradshaw, ${ }^{4}$ Christopher K Fairley ${ }^{1}$
}

\section{ABSTRACT}

Background Australia provided free quadrivalent human papillomavirus vaccines to $12-18$-year-old girls and women aged $\leq 26$ years from mid-2007 until the end of 2009. After this time, only girls aged $12-13$ years had access to free vaccines.

Methods Before and after the study, of the proportion of new patients attending Melbourne Sexual Health Centre from mid-2004 to mid-2011, diagnosed with genital warts (GW) by risk group.

Results From July 2004 to June 2011, 52454 new patients were seen at Melbourne Sexual Health Centre and 5021 (9.6\%, 95\% Cl 9.3\% to 9.8\%) were diagnosed with GW. From July 2004 to June 2007, the proportions with GW either increased or did not change in all groups. Comparing the two 12-month periods of 2007/2008 and 2010/2011, GW declined in women under 21 years from $18.6 \%$ to $1.9 \%$ and in heterosexual men under 21 years from $22.9 \%$ to $2.9 \%$. The ORs per year for diagnosis of GW adjusted for number of sexual partners from July 2007 until June 2011 in women and heterosexual men $<21$ years were $0.44(95 \% \mathrm{Cl} 0.32$ to 0.58$)$ and 0.42 $(95 \% \mathrm{Cl} 0.31$ to 0.60$)$, respectively. There was no significant change in $\mathrm{GW}$ in women $\geq 30$ years $(\mathrm{OR} 0.97$, $95 \% \mathrm{Cl} 0.84$ to 1.12 ), heterosexual men $\geq 30$ years (OR $0.97,95 \% \mathrm{Cl} 0.89$ to 1.06 ) or in homosexual men (OR $0.95,95 \% \mathrm{Cl} 0.85$ to 1.07 ).

Conclusion The dramatic decline and near disappearance of GW in women and men under 21 years of age, 4 years after commencing this programme, suggest that the basic reproductive rate has fallen below one.

\section{INTRODUCTION}

In April 2007, Australia began vaccinating women aged 12-27 years against human papillomavirus (HPV) genotypes 6, 11, 16 and 18 using the quadrivalent HPV vaccine (Gardasil; CSL Biotherapies, Melbourne Victoria, Australia). We previously reported that by the end of 2008, presentations of genital warts (GW) at the Melbourne Sexual Health Centre (MSHC) had halved in women younger than 28 years, declined to a lesser degree in heterosexual men but not changed in homosexual men or women aged 28 years or older. ${ }^{1}$ By the end of 2009, an Australia-wide surveillance programme using data from eight sexual health centres ${ }^{2}$ confirmed our initial observations and also showed that the changes in younger women were restricted to Australians who were eligible for the free vaccine and were not seen in non-residents. ${ }^{2}$ By the end of 2009, however, the decline in younger women had slowed substantially raising doubts as to whether the vaccination programme would eventually eliminate GWs or merely reduce their incidence. $^{2}$ Furthermore, the national data do not currently include the number of sexual partners so they cannot be adjusted for any changes in sexual risk that may explain changes seen in GWs presentations.

In this analysis, we update the trends in GWs at MSHC to the end of June 2011, adjusting for sexual risk, and we explore trends in women young enough to have been vaccinated at school before a significant proportion may have become sexually active. $^{3}$

\section{METHODS}

We extracted data from the patient management database to investigate the proportion of new clients who were diagnosed with GWs attending MSHC between 1 July 2004 and 30 June 2011. MSHC is the major public sexual health clinic serving Melbourne, a city of 4 million people. The Centre provides a walk-in triage service that prioritises access to the centre for clients who belong to risk groups or who have symptoms, and the same triage process has been in place since $2001{ }^{4}$ Referrals are not required and services are free of charge. GWs are not a notifiable infection in any state or territory of Australia.

Clinical and epidemiological data are routinely entered into the clinic electronic database during consultations with every new client. These data include the diagnosis and the number and gender of sexual partners in the previous 12 months. Demographic data include the country of birth and, for those born overseas, year of arrival in Australia. In this analysis, those born outside Australia and who had arrived $\geq 3$ years before their visit were classified as 'non-residents' as they were unlikely to be eligible for the HPV vaccination programme, which was only available to Australian citizens or permanent residents. Obtaining Australian citizenship or permanent residence takes at least 3 years. ${ }^{5}$ From 2009, women were asked if they had ever had the HPV vaccine.

The quadrivalent HPV vaccine was made available in Australia free of charge from April 2007 to girls aged 12 and 13 years in an ongoing school- 
based programme and to a catch-up group of 13-18-year-old girls in a largely school-based programme until the end of 2009. From July 2007, it became available free of charge through general practitioners and community immunisation clinics for young women, aged up to and including 26 years, but was no longer available to this group after the end of 2009. There were no programmes for men or older women, although the quadrivalent vaccine was available for approximately $A \$ 450$ for men aged $9-26$ years and for women aged $9-45$ years. The bivalent vaccine (Cervarix; GlaxoSmithKline Biologicals, Rixensart, Belgium) is also commercially available for women of the same age but is not subsidised.

\section{Statistical analysis}

In figure 1, the proportion of new clients with a GW diagnosis was calculated by dividing the number of GW diagnoses by the number of new clients seen in the relevant risk group in 6-month periods. ORs and 95\% CIs for a diagnosis of warts in each additional 12-month period after 1 July 2007 were calculated using logistic regression and adjusted for the number of sexual partners in the previous 12 months. The same analysis was also undertaken for the 3-year period from 1 July 2004. These analyses were stratified by different age groups and risk groups. All calculations were performed in Stata V.11 (StataCorp).

Our primary objective was to determine the population effect of the HPV vaccination programme in Melbourne in women and in men through herd immunity, so we excluded non-residents from all but not the first logistic regression because the majority of their new sexual partners in Australia are also recent arrivals. ${ }^{6}$ We examined three groups of women defined by their age on the day they attended ( $<21,21-29$ and $\geq 30$ years). No women $\geq 30$ years of age would have been eligible for free vaccine because all were older than 26 years when the programme began in 2007. With each year since 2007, an increasing proportion of women 21-29 years of age would have been eligible for the vaccination programme. All women $<21$ years of age would have been eligible for the vaccination programme in every year since 2007 and an increasing proportion would have received their vaccine at school at a time when most had not yet become sexually active. Girls are vaccinated in their first year of high school (12-13 years of age), and by age 16, about one in four have had vaginal intercourse. ${ }^{3}$

\section{Presentations with warts in men and women $<21$ years, and MSM all ages, July 2004 to end June} 2011 Vaccination program commences

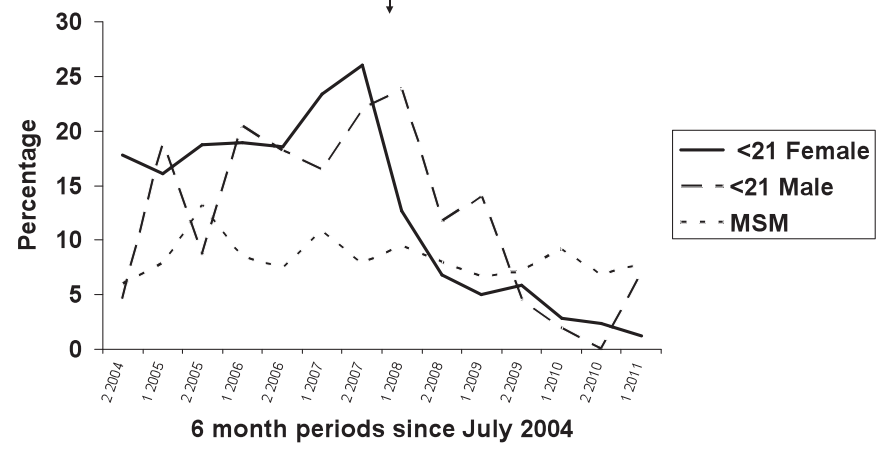

Figure 1 Proportion of patients aged $<21$ years, diagnosed as having genital warts by risk group compared with MSM of all ages: MSM, men who have sex with men, men $<21$ years excluded MSM, and non-residents excluded.
The HPV vaccine registry estimated vaccine coverage at the end of the catch-up period at $80 \%$ for two doses and $73 \%$ for three doses for girls aged 12-13 years. Coverage was lower with increasing age, with two- and three-dose coverage, respectively, for women aged $16-17$ years was $75 \%$ and $72 \%$ and for women aged $18-19$ years it was $53 \%$ and $30 \%$; for women aged $20-26$ years it was $38 \%$ and $42 \%{ }^{7}$ Coverage rates for three doses in girls aged 15 years of age in 2009 were somewhat higher in Victoria $(76.1 \%)$ than in Australia as a whole $(70.7 \%){ }^{8}$

The study was approved by the Alfred Hospital ethics committee as involving 'negligible risk' and did not require a formal ethics submission.

\section{RESULTS}

From 1 July 2004 to 30 June 2011, 52454 new patients were seen at MSHC and 5021 (9.6\%, 95\% CI 9.3\% to $9.8 \%$ ) were diagnosed with GWs. The proportion of individuals diagnosed each year with GWs by age and risk group is shown in table 1 . The largest declines between the 2007/2008 and 2010/2011 periods occurred in women under 21 years of age (a reduction from $18.6 \%$ to $1.9 \%$ ) and in heterosexual men under 21 years of age (reduction from $22.9 \%$ to $2.9 \%$ ). From 1 July 2010 to 30 June 2011, only four cases of warts occurred in heterosexual women $<21$ years of age compared with between 46 and 66 cases per annum before July 2007. Figure 1 shows these data in six monthly intervals.

Before July 2007, GW diagnoses in women increased significantly with each year (OR 1.16, 95\% CI 1.05 to 1.28) and were unchanged in all other groups (table 2). After July 2007, wart diagnoses decreased significantly in women $<21$ years of age or 22-29 years of age but not older women. Similarly, wart diagnoses decreased in heterosexual men aged $<21$ years and in those aged 22-29 years but not in older heterosexual men. After July 2007, wart diagnoses did not change in men who have sex with men (MSM) or non-residents. Among women who reported receiving the HPV vaccine, the adjusted OR for a diagnosis of warts was 0.29 (95\% CI 0.13 to 0.65 ) in 2010/2011 compared with $2009 / 2010$.

\section{DISCUSSION}

We have demonstrated the near disappearance of GWs in heterosexual women and men $<21$ years of age attending a large sexual health service drawn from a population that started vaccinating girls and young women for HPV only 4 years ago. This reduction in women and men under 21 years of age has occurred without any corresponding reduction in GWs in women over 30 years of age, MSM and non-residents. None of these latter groups were eligible for the free vaccination programme. Our analyses were adjusted for the number of sexual partners in the previous 12 months adding strength to the findings. The data provide the first evidence that a vaccination programme with a $70 \%$ coverage of young women may lead to the near disappearance of GWs from the heterosexual population and suggest that the reproductive rate of HPV types 6 and 11 in young Australians is now below one. Unfortunately, the data also indicate that MSM, whose rate of anal cancer is at least as high as cervical cancer in women, are receiving no benefit from the current HPV vaccination programme. ${ }^{9}$

Our study has a number of limitations that are important to consider in interpreting the results. Our data come from a single centre and the findings could be different in other parts of Australia. Furthermore, our findings could be explained by unmeasured confounding. We consider these possibilities to be unlikely for a number of reasons including the similarity 
Table 1 Number (N) and percentage of new patients diagnosed as having genital warts at the Melbourne Sexual Health Centre, by year and risk group, from 1 July 2004 to 30 June 2011

\begin{tabular}{|c|c|c|c|c|c|c|c|}
\hline Characteristics & $\begin{array}{l}2004 / 2005 \\
N(\%)\end{array}$ & $\begin{array}{l}2005 / 2006 \\
N(\%)\end{array}$ & $\begin{array}{l}2006 / 2007 \\
N(\%)\end{array}$ & $\begin{array}{l}2007 / 2008 \\
N(\%)\end{array}$ & $\begin{array}{l}2008 / 2009 \\
N(\%)\end{array}$ & $\begin{array}{l}2009 / 2010 \\
\text { N (\%) }\end{array}$ & $\begin{array}{l}2010 / 2011 \\
N(\%)\end{array}$ \\
\hline All patients* & $750(11.0)$ & $804(11.8)$ & $818(11.7)$ & $697(9.9)$ & $665(8.4)$ & $665(8.0)$ & $622(7.3)$ \\
\hline All, excluding non-residents & $618(12.1)$ & $652(13.0)$ & $658(13.1)$ & $530(11.4)$ & $473(9.7)$ & $442(9.0)$ & $411(7.8)$ \\
\hline Non-residents* & $80(9.1)$ & $92(8.3)$ & $87(8.0)$ & $118(7.6)$ & $129(6.5)$ & $136(6.6)$ & $163(6.9)$ \\
\hline All women & $205(10.4)$ & $216(11.6)$ & $253(13.0)$ & $183(10.8)$ & $118(7.1)$ & $116(6.7)$ & $88(5.0)$ \\
\hline Women, <21 yr & 46 (16.9) & $56(18.8)$ & $66(20.9)$ & $42(18.6)$ & $13(6.0)$ & $11(4.5)$ & 4 (1.9) \\
\hline Women, $21-29 \mathrm{yr}$ & $116(12.3)$ & $117(13.1)$ & $138(14.2)$ & $93(10.8)$ & $60(7.1)$ & $59(6.6)$ & $35(3.7)$ \\
\hline Women, $\geq 30 \mathrm{yr}$ & $43(5.7)$ & $43(6.4)$ & $49(7.5)$ & $48(8.0)$ & $45(7.5)$ & $45(9.1)$ & $49(7.9)$ \\
\hline MSW & $319(15.5)$ & $329(15.8)$ & $291(15.2)$ & $253(14.3)$ & $263(13.7)$ & $224(11.5)$ & 234 (10.8) \\
\hline MSW, <21 yr & $12(10.5)$ & $16(13.4)$ & $25(17.2)$ & $25(22.9)$ & 13 (12.9) & $3(3.1)$ & $4(2.9)$ \\
\hline MSW, $21-29 \mathrm{yr}$ & $143(16.6)$ & $167(19.6)$ & $150(18.5)$ & $122(16.1)$ & $141(16.6)$ & $123(13.7)$ & $114(11.7)$ \\
\hline MSW, $\geq 30 \mathrm{yr}$ & $164(15.2)$ & $146(13.2)$ & $116(12.1)$ & $106(11.8)$ & $109(11.3)$ & $98(10.4)$ & $116(11)$ \\
\hline MSM & $43(6.9)$ & $71(10.6)$ & $63(9.2)$ & $60(8.7)$ & $56(7.2)$ & $67(8.1)$ & $61(7.3)$ \\
\hline Women prior HPV vaccine & & & & & & $27(5.7)$ & $8(1.5)$ \\
\hline Total number of new patients & & 6971 & 6764 & 6825 & 6948 & 7676 & 8046 \\
\hline
\end{tabular}

6319 individuals were not born in Australia but did not complete year of arrival at registration.

*Non-residents were those not born in Australia, whose year of arrival was within 3 years of consultation. All analyses except the first row exclude non-residents unless ‘* is shown.

HPV, human papillomavirus; MSM, men who have sex with men; MSW, men who have sex with women.

between our earlier findings to the end of $2008^{1}$ and the findings of the Australia-wide surveillance programme, ${ }^{2}$ the fact that our data have been adjusted for sexual behaviour which is the most important predictor of GW, the very large effect size that we have demonstrated and finally the absence of a decline in GW in unvaccinated groups in any risk group before July 2007. In addition, previous work has shown an increasing prevalence of other sexually transmitted infections among heterosexuals attending MSHC, which would make a fall in GW without vaccination even more unlikely ${ }^{10} 11$

Recent data from Australia ${ }^{12}$ demonstrate a similar decline in rates of high-grade cervical abnormalities in young women, suggesting that the prevalence of HPV types 16 and 18 may also be declining rapidly. This effect was most apparent in data from 19158 women aged <18 years who were screened over

Table 2 Adjusted ORs for genital warts per year in new patients at Melbourne Sexual Health Centre, for two time periods before and after 1 July 2007

\begin{tabular}{|c|c|c|}
\hline Patient category/risk group & $\begin{array}{l}\text { July } 2004 \text { to June } \\
2007 \text {, adjusted OR } \\
\text { and } 95 \% \mathrm{CI}\end{array}$ & $\begin{array}{l}\text { July } 2007 \text { to June } \\
2011 \text {, adjusted OR } \\
\text { and } 95 \% \mathrm{Cl}\end{array}$ \\
\hline $\begin{array}{l}\text { All patients, including } \\
\text { non-residents* }\end{array}$ & $1.05(0.99$ to 1.11$)$ & $0.89(0.86$ to 0.93$)$ \\
\hline $\begin{array}{l}\text { All patients excluding } \\
\text { non-residents }\end{array}$ & $1.06(1.00$ to 1.13$)$ & $0.86(0.82$ to 0.90$)$ \\
\hline Non-residents* & $0.91(0.77$ to 1.08$)$ & $0.98(0.90$ to 1.07$)$ \\
\hline Women, all ages & $1.16(1.05$ to 1.28$)$ & $0.75(0.69$ to 0.82$)$ \\
\hline Women, $<21$ years & $1.11(0.90$ to 1.38$)$ & $0.44(0.32$ to 0.58$)$ \\
\hline Women, $22-29$ years & $1.12(0.98$ to 1.29$)$ & $0.70(0.62$ to 0.80$)$ \\
\hline Women, $\geq 30$ years & $1.22(0.97$ to 1.53$)$ & $0.97(0.84$ to 1.12$)$ \\
\hline $\begin{array}{l}\text { MSW (exclusively heterosexual } \\
\text { men) all ages }\end{array}$ & 0.99 (0.91 to 1.08$)$ & $0.89(0.84$ to 0.95$)$ \\
\hline MSW, $<21$ years & 1.32 (0.92 to 1.90$)$ & $0.42(0.31$ to 0.60$)$ \\
\hline MSW, 22-29 years & $1.07(0.94$ to 1.21$)$ & $0.87(0.80$ to 0.95$)$ \\
\hline MSW, $\geq 30$ years & $0.88(0.77$ to 1.00$)$ & 0.97 (0.89 to 1.06$)$ \\
\hline MSM, all ages & $1.15(0.95$ to 1.39$)$ & $0.95(0.85$ to 1.07$)$ \\
\hline
\end{tabular}

6319 individuals were not born in Australia but did not complete year of arrival at registration.

All ORs adjusted for number of partners (opposite sex partners for heterosexuals and male partners for MSM).

*Non-residents were those not born in Australia, whose year of arrival was within 3 years of consultation. All analyses except the first row exclude non-residents unless '*' is shown. MSM, men who have sex with men; MSW, men who have sex with women.
7 years (Australian guidelines throughout this period did not recommend cervical screening before 18 years of age).

The contrast between the marked decline in presentations of GWs in women $<21$ years of age and the less marked decline in those aged 21-29 years, raises a number of important hypotheses. By 2011, all the women aged 21-29 years would have been eligible for the free catch-up HPV vaccine programme, but we did not see a similar decline in GWs to that seen in younger women. One possibility is that a higher proportion women aged 21-29 years were already infected with HPV type 6 or 11 and that there may be a substantial delay in the appearance of GWs after HPV infection. Previous studies indicated that genital warts appear a mean of 2.9 months (IOR 0-5.7 months) after the detection of HPV type 6/11 DNA or a mean of 2.8 months (range 0-8 months) after sex with someone with warts. ${ }^{13} 14$ However, a more recent study by Garland et a ${ }^{15}$ reported warts appearing up to 45 months after the first detection of HPV type 6 DNA. This suggests that a significant 'wash out' period may exist after HPV vaccination when lesions could emerge from $\mathrm{HPV}$ infection acquired before vaccination. In support of this point, we saw the decline in GW continuing until June 2011 in women who reported having received the HPV vaccine, which was only provided free up to the end of 2009. There are two further possible explanations for the difference in rate of decline between the two younger age groups in women. The first may be that herd immunity is weaker in the older women (21-29 years of age) who tend on average to have sex with men

\section{Key messages}

- Australia began a free quadrivalent HPV vaccination programme in mid-2007 for schoolgirls and women $<28$ years of age with coverage of about $70 \%$.

- Since July 2007, genital warts have declined in our clinic by almost $90 \%$ in women and heterosexual men $<21$ years of age, with smaller declines in the same groups aged 21-29 years.

- Since July 2007, there has been no decline in genital warts in women or heterosexual men over 29 years of age, men who have sex with men or non-residents. 
$1-5$ years older than they are. ${ }^{16}$ Second, the significantly lower HPV vaccine coverage during the catch-up programme for women older than school age may have reduced the population effectiveness of the vaccine. ${ }^{7}$

We conclude that the heterosexual transmission of GWs will become rare in Australia as a result of the HPV vaccination programme. Addressing the continuing transmission of warts among MSM will be the next challenge for health policy makers.

Acknowledgements We would like to thank Afrizal and Jun Kit Sze for the extraction of the data from MSHC.

Funding JSH holds National Health and Medical Research Council Career Development Awards ID 454779. TRHR holds an Australian Postgraduate Award. No funding was obtained to undertake this study.

Competing interests CKF, JSH and BD have received honoraria from CSL Biotherapies. BD has received honoraria from GlaxoSmithKline and Merck. BD and CKF have received research funding from CSL Biotherapies. CKF owns shares in CSL Biotherapies the manufacturer for Gardasil and has received honoraria from Merck. MYC, TRHR and CSB have no conflicts of interest.

Ethics approval This study was approved by Research and Ethics unit, The Alfred Hospital.

Contributors CKF and BD designed the study. TRHR, CKF and JSH analysed the data. All authors contributed to the manuscript.

Provenance and peer review Not commissioned; externally peer reviewed.

\section{REFERENCES}

1. Fairley CK, Hocking JS, Gurrin LC, et al. Rapid decline in presentations of genital warts after the implementation of a national quadrivalent human papillomavirus vaccination programme for young women. Sex Transm Infect 2009;85:499-502.

2. Donovan B, Franklin N, Guy R, et al. Quadrivalent human papillomavirus vaccination and trends in genital warts in Australia: analysis of national sentinel surveillance data. Lancet Infect Dis 2011:11:39-44.
3. Smith A, Agius A, Mitchell A, et al. Secondary Students and Sexual Health 2008Results of the 4th National Survey of Australian Secondary Students, HIVIAIDS and Sexual Health. Melbourne Australia: Australian Research Centre in Sex, Health \& Society (ARCSHS), La Trobe University, 2008.

4. Tideman RL, Pitts MK, Fairley CK. Effects of a change from an appointment service to a walk-in triage service at a sexual health centre. Int J STD AIDS 2003:14:793-5.

5. E-Business Systems, Residence Requirements Calculator. Australian Government, Department of Immigration \& Citizenship, 2011. https://www.ecom.immi.gov.au/citz/ startIntervalCalc.do (accessed 9 Jun 2011).

6. Davies SC, Karagiannis T, Headon V, et al. Prevalence of genital chlamydial infection among a community sample of young international backpackers in Sydney, Australia. Int J STD AIDS 2011:22:160-4.

7. Gertig DM, Brotherton JM, Saville M. Measuring human papillomavirus (HPV) vaccination coverage and the role of the National HPV Vaccination Program Register, Australia. Sex Health 2011:8:171-8.

8. Immunise Australia Program, Human Papillomavirus (HPV) - The National HPV Vaccination Program Register. Australian Govenment, Department of Health \& Ageing, 2011. http://www.immunise.health.gov.au/internet/immunise/publishing.nsf/ Content/immunise-hpv\#figure1 (accessed 29 Jun 2011).

9. Grulich $\mathbf{A E}$, Jin F, Conway EL, et al. Cancers attributable to human papillomavirus infection. Sex Health 2010;7:244-52.

10. O'Rourke KM, Fairley CK, Samaranayake A, et al. Trends in chlamydia positivity over time among women in Melbourne Australia, 2003 to 2007. Sex Transm Dis 2009;36:763-7.

11. Vodstrcil LA, Fairley CK, Fehler G, et al. Trends in chlamydia and gonorrhea positivity among heterosexual men and men who have sex with men attending a large urban sexual health service in Australia, 2002-2009. BMC Infect Dis 2011;11:158.

12. Brotherton JM, Fridman M, May CL, et al. Early effect of the HPV vaccination programme on cervical abnormalities in Victoria, Australia: an ecological study. Lancet 2011;377:2085-92.

13. Winer RL, Kiviat NB, Hughes JP, et al. Development and duration of Human Papillomavirus Lessions after initial infection. J Infect Dis 2005;191:731-8.

14. Oriel JD. Natural history of genital warts. Br J Ven Dis 1971:47:1-12

15. Garland SM, Steben M, Sings HL, et al. Natural history of genital warts: analysis of the placebo arm of 2 randomized phase III trials of a quadrivalent human papillomavirus (Types 6, 11, 16, and 18) vaccine. J Infect Dis 2009;199:805-14.

16. de Visser RO, Smith $A$, Rissel $C$, et al. Heterosexual experience and recent heterosexual encounters among a representative sample of adults. Aust N Z J Public Health 2003:27:146-54. 